\title{
An Active Teaching Approach to Business Management: Gender and Ethnic Service Learning Self-Reflections
}

\author{
Roxanne Helm-Stevens (Corresponding author) \\ MBA, HPT, CT \\ Program Chair, MHROD \\ School of Business and Management, Azusa Pacific University, Azusa, CA \\ E-mail: rhelm@apu.edu
}

Orlando V. Griego

Chair of MBA Program, Associate Dean, Professor

School of Business and Management, Azusa Pacific University, Azusa, CA,

E-mail: ogriego@apu.edu

\begin{abstract}
College business students, as part of a requisite undergraduate business management course, were assigned a service learning project. A component of the service-learning project was to teach business and management related curriculum to at-risk high school students.

The undergraduate students, consisting of gender and ethnic mixes were then assessed in their perceptions of the following service learning position: leadership to at-risk students, relationships to at-risk students, making a difference to at-risk students, teamwork effectiveness, service learning effectiveness, and role modeling to at-risk students. A repeated measures ANOVA and factorial ANOVA were used to assess effects. Significant differences were noted.
\end{abstract}

Keywords: Learning, Risk, Service-learning 


\section{$\underline{\Lambda \text { Macrothink }}$}

\section{Heading Level-1}

\subsection{Background of the Study}

Service learning joins service with learning in "a teaching and learning strategy that integrates meaningful community service with instruction and reflection to enrich the learning experience, teach civic responsibility, and strengthen communities" (The National Service-Learning Clearinghouse, 2007). The purpose of service learning is to provide learning for both the provider and the community member of the service. Students engaged in service learning efforts are challenged via action learning and reflective learning.

Service learning has potential for powerful learning by linking academic with practical knowledge development. Classroom theories take on new meaning as students engage in "real" world application and learning. The advantage of service learning enables students to link experience with classroom content. Moreover, the real world duties engage students to the community and prepare them for practical learning outside the class.

By taking part in service learning, students associate personal and social development with academic and cognitive development. Eyler and Giles (1999) recapped their research about service-learning this way: "experience enhances understanding; understanding leads to more effective action." Service learning continues to grow annually. The 2006 national Campus Compact survey of colleges demonstrated that $90 \%$ of colleges included some form of service to the community, $72 \%$ included student civic engagement, and $62 \%$ included student civic learning statements in their strategic plans. The mission of higher education is moving more and more to serving the community (Kezar, 2002; Oates \& Leavitt, 2003; Watts, 2003).

Service-learning has focused on identifying the concept of service-learning and new research questions regarding its definition (Steinke \& Buresh, 2002). Recent research has focused on determining areas impacting student outcomes or integrating impact outcomes into service-learning courses (Bringle \& Hatcher, 1996; Moely, Mercer, Ilustre, Miron, \& McFarland, 2002). There is a body of information documenting the effectiveness of service learning (Batchelder \& Root, 1994; Eyler, Giles \& Braxton, 1997; Eyler \& Giles, 1999; Hesser, 1995). However, little attention has been given to service-learning research with regard to personal reflection components to improve students' learning outcomes such as relationships, communication, spiritual perceptions, role-modeling, making a difference, leadership, service learning perceptions, and teamwork. More importantly, gender and ethnicity have not been assessed empirically with these reflective components. This study seeks to determine those key insightful factors.

\subsection{Subjects}

The participants in the survey were students enrolled in an undergraduate- senior levelbusiness management course at a private university located in Azusa, California. Of these students, $89.9 \%$ were business majors. This was largely due to the course in which the study took place being a required, senior-level course for students seeking to major in business. 


\section{Mll Macrothink}

Enrollment at the University (2008), for the year of 2007 was noted at $63.16 \%$ white, non-Hispanic, $14.41 \%$ Hispanic, $7.22 \%$ Asian or Pacific Islander, $4.7 \%$ Black and .48\% Asian or Pacific Islander.

\subsection{Service Learning Site Demographics}

The 2000 U.S. Census Bureau declares the following demographics: $15.8 \%$ of the population of Azusa, California has some form of college degree, and $14.2 \%$ have a bachelors' degree or higher. Additionally, the Azusa Unified School District reports the following demographics for their student population: 84.2\% Hispanic, 9.4\% Caucasian, 3.1\% African American, $1.9 \%$ Filipino, and $1.3 \%$ Asian or Pacific Islander.

\subsection{Hypotheses}

The objective was to have students gain insight into themselves, the at-risk students they taught, and their service learning experience. Service learning can provide an outlet for performance improvement in many areas. Consequently, the following null hypotheses were established for the study:

Hypothesis 1: There is no significant difference across self-perceptions of leadership, role modeling, relationships, teamwork, communication, making a difference, service learning, and spiritual support.

Hypothesis 2: There is no significant main and interaction effect between gender and ethnicity across self-perceptions of leadership, role modeling, relationships, teamwork, communication, making a difference, service learning, spiritual support, and GPA.

\section{Methodology}

\subsection{Subjects}

One hundred and fourteen respondents took part in the research at a private faith-based university. There were 55 males, 57 females, and 2 not answered. Ages ranged between 20 to 24 years old $(\mathrm{M}=21.07, \mathrm{SD}=0.92)$. The majority were seniors $(70.50 \%)$ with the remaining being juniors $(28.60 \%)$ and one sophomore $(0.90 \%)$. The racial distribution of the students was $80 \%$ Caucasian and $20 \%$ Minority.

\subsection{Procedures}

To assess the benefits of service learning on various constructs, participants were asked to do a paper and pencil self-assessment of their service learning experience and their relationships to at-risk students, teaching of at-risk students, role-modeling capabilities, perception that they made a difference, leadership commitment, spiritual support sought, and teamwork abilities. Two convenience samples were used over the course of two semesters from an Organizational Behavior course that had a service learning requirement. 


\section{Macrothink

Participants were invited to participate but were not required to take part in the service learning study. To reduce potential bias effects, the self-assessment instrument was administered separately with instructions not to share information. Confidentiality was guaranteed. Moreover, the participants were informed of the purpose of the study, warned of any risks and inconveniences, explained the benefits of participating, and offered the opportunity to be removed from the study at any time.

\subsection{Instrumentation}

A self-reporting instrument was developed covering eight constructs: Relationship to At-Risk Students, Communicating to At-Risk Students, Role Modeling to At-Risk Students, Making a Difference to At-Risk Students, Leadership Commitment, Service Learning Effectiveness, Seeking Spiritual Support, and Teamwork. In addition, GPA was assessment against gender and ethnicity.

The original instrument contained 48 questions and was tailored to 46 questions following reliability analysis. Cronbach's alphas indicated solid reliability (alpha $=.72$ to .89 ) for each construct. See table 1 for details of each construct.

The eight constructs were designed to measure respondent self-perceptions. Following is a sample of the questions for each construct:

Table 1. Reliability Analysis of Constructs

\begin{tabular}{lc}
\hline Construct & Alpha \\
\hline Relationship to At-Risk Students & .81 \\
Communicating to At-Risk Students & .72 \\
Role Modeling to At-Risk Students & .82 \\
Making a Difference to At-Risk Students & .78 \\
Leadership Commitment & .81 \\
Service Learning Effectiveness & .84 \\
Seeking Spiritual Support & .89 \\
Teamwork & .88 \\
\hline
\end{tabular}

\section{Relationship to At-Risk Students}

1. I felt I was effective at supporting at-risk students

2. I tried to find common ground with my students

\section{Communicating to At-Risk Students}

1. I feel sure I communicated important ideas to at-risk students

2. I feel confident I communicated positive messages to at-risk students

\section{Role Modeling to At-Risk Students}

1. I believe I led by "doing" rather than simply by "telling."

2. My actions symbolized success and accomplishment to at-risk students. 


\section{Macrothink

\section{Making a Difference to At-Risk Students}

1. I am certain I made a difference in the lives of my students

2. I sought to impact my student's lives

\section{Leadership Commitment}

1. I engage my student's hearts, emotions, and passions

2. I inspired students to work at their full capabilities

\section{Service Learning Effectiveness}

1. I had a sense of "usefulness" during my service learning experience

2. My service learning experience impacted me for the better

\section{Seeking Spiritual Support}

1. During my service learning experience, I sought God's love and care in my daily life

2. I trusted that God was by my side during this service learning experience

\section{Teamwork}

1. I feel team members met their commitments to each other

2. In my team, members were committed to building relationships for success

\subsection{Analysis}

Statistical analysis was accomplished using SPSS 15.0 (Statistical Package for the Social Sciences). In addition to descriptive statistics analysis, further investigation was done using repeated measures ANOVA and a factorial ANOVA. A repeated measures ANOVA is useful in assessing any repeated factors. In this case, seven constructs were selected for repeated self-assessments of respondent's self-perceptions. A factorial ANOVA was then used to assess the main and interaction effects of gender and ethnicity across each of the constructs. In addition, GPA was added to the factorial ANOVA analysis as a dependent variable.

\subsection{Findings}

\subsubsection{Test of Hypothesis 1 Using Repeated Measures ANOVA}

The first null hypothesis stated there were no significant different across self-perceptions of leadership, role modeling, relationships, teamwork, spiritual support, communication, and making a difference. The null hypothesis was rejected.

Using repeated measures ANOVA across the eight constructs, the results were significant, $\mathrm{F}(1$, $5.52)=11.79, \mathrm{p}<.01$. Mauchly's test of sphericity was not assumed so Greenhouse-Geisser was used to determine significance. Further post hoc comparisons indicate the following significant difference within subject:

Relationships ( $M=3.23)$, Role Modeling ( $M=3.29)$, Service Learning $(M=3.22)$, Teamwork $(M=3.36)$, and Spiritual Support $(M=3.27)$ were rated significantly higher than Communication $(\mathrm{M}=3.06)$, Making a Difference $(\mathrm{M}=3.11)$, and Leadership $(\mathrm{M}=3.08)$. In addition, Teamwork $(M=3.36)$ was rated significantly higher in all areas except Role Modeling. 
Figure 1 provides a graphic representation of the significant differences.

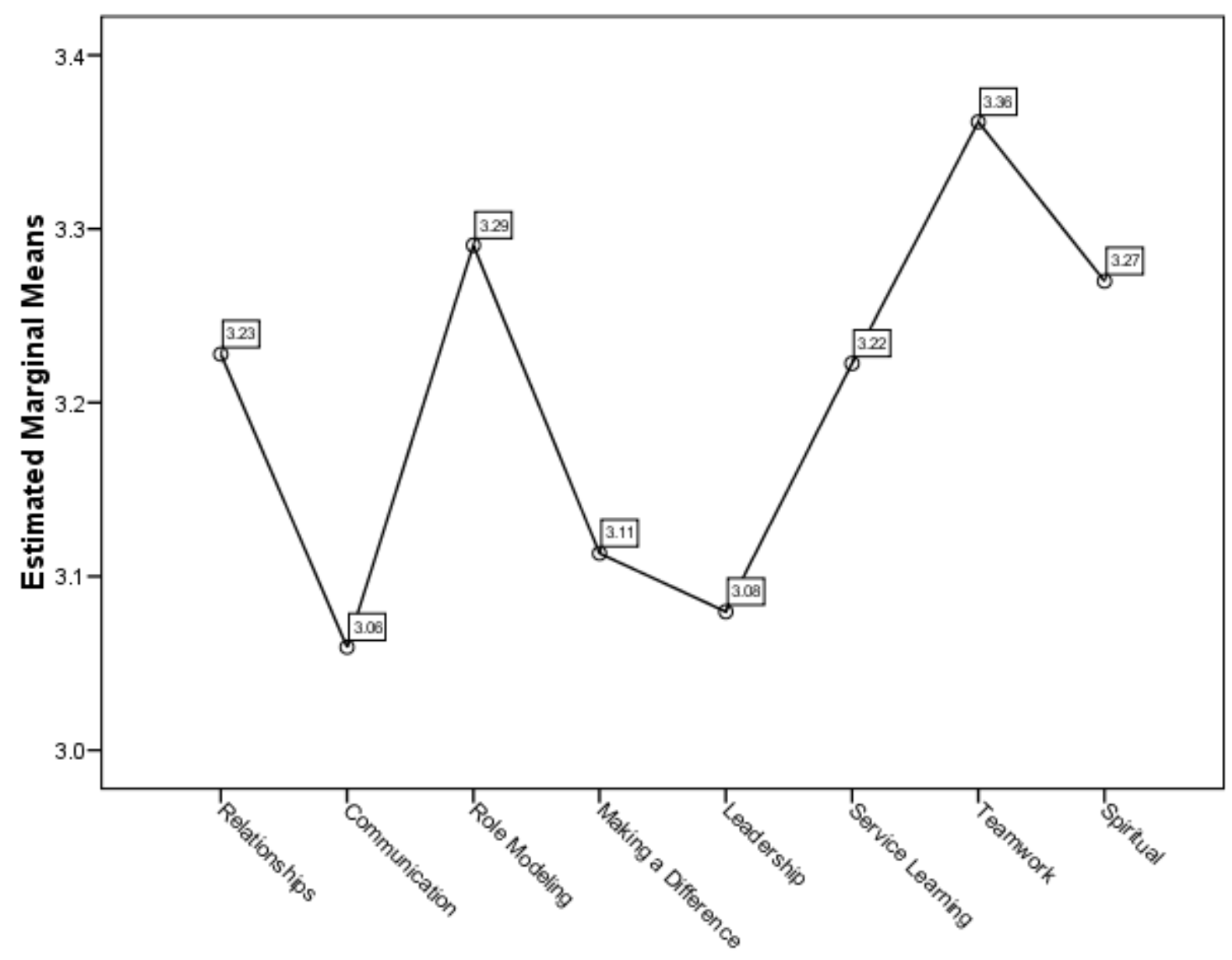

Figure 1. Graphic Representation of the Repeated Measures ANOVA Across Constructs

Table 2. Mean Statistics for Repeated Measures ANOVA

Mean Std. Deviation N

Relationship to At-Risk Students

$3.23 \quad .46 \quad 114$

Communicating to At-Risk Students

$\begin{array}{lll}3.06 & .42 \quad 114\end{array}$

Role Modeling to At-Risk Students

$\begin{array}{lll}3.29 & .51 \quad 114\end{array}$

Making a Difference to At-Risk Students

$\begin{array}{lll}3.11 & .45 & 114\end{array}$

Leadership Commitment

$\begin{array}{lll}3.08 & .46 & 114\end{array}$

Service Learning

3.22

.51

113

Working in Teams

3.36

.47

113

Spiritual Support 


\subsubsection{Factorial ANOVA}

Hypothesis 2 stated that there is no significant main and interaction effect between gender and ethnicity across self-perceptions of leadership, role modeling, relationships, teamwork, spiritual support, communication, making a difference, service learning effectiveness, and GPA. The hypothesis was rejected. There were significant differences.

Using a factorial ANOVA, both gender and ethnicity's main effects were assessed across nine constructs. Most main effects for gender were not significant. One, gender across teamwork, was significant, $\mathrm{F}(1,107)=5.12, \mathrm{p}=.03$. Males $(\mathrm{M}=3.42)$ rated teamwork significantly higher than females $(M=3.35)$. There were no significant differences of ethnicity across any of the constructs.

There were significant interaction effects between gender and ethnicity across some of the nine constructs. Table 3 shows a significant interaction between Gender and Ethnicity across three factors. Relationship to At-Risk Students $(\mathrm{F}(1,107)=4.43, \mathrm{p}=.04)$, Making a Difference $(\mathrm{F}(1,107)=5.47, \mathrm{p}=.02)$, and Working in Teams $(\mathrm{F}(1,107)=7.16, \mathrm{p}=.01)$. Additionally, Figures $2-4$ provide a graphical representation of the significant interaction effects.

We can use the estimated marginal means of each construct to determine the nature of the interaction. In each significant construct Male Minorities and Female Caucasians had higher mean scores than Female Minorities and Male Caucasians. No other interaction effects were noted with any of the other factors. See Table 4 for a breakdown of mean scores for those significant interactions.

Table 3. Factorial ANOVA

Tests of Between-Subjects Effects

\begin{tabular}{|c|c|c|c|c|c|c|c|}
\hline Source & & Dependent Variable & $\begin{array}{l}\text { Type III } \\
\text { Sum of } \\
\text { Squares }\end{array}$ & df & $\begin{array}{l}\text { Mean } \\
\text { Square }\end{array}$ & $\mathrm{F}$ & Sig. \\
\hline \multirow[t]{6}{*}{$\begin{array}{l}\text { Gender } \\
\text { ethnic.2grps }\end{array}$} & $*$ & $\begin{array}{l}\text { Relationship } \\
\text { At-Risk Students }\end{array}$ & .954 & 1 & .954 & 4.430 & .038 \\
\hline & & $\begin{array}{l}\text { Communicating to } \\
\text { At-Risk Students }\end{array}$ & .596 & 1 & .596 & 3.304 & .072 \\
\hline & & $\begin{array}{l}\text { Role-Modeling } \\
\text { At-Risk Students }\end{array}$ & .761 & 1 & .761 & 2.915 & .091 \\
\hline & & $\begin{array}{l}\text { Making a Difference } \\
\text { to At-Risk Students }\end{array}$ & 1.057 & 1 & 1.057 & 5.472 & .021 \\
\hline & & $\begin{array}{l}\text { Leadership } \\
\text { Commitment }\end{array}$ & .581 & 1 & .581 & 2.593 & .110 \\
\hline & & Service Learning & .832 & 1 & .832 & 3.277 & .073 \\
\hline
\end{tabular}


Working inTeams

1.463

1

1.463

7.164

.009

Seeking Spiritual

Support

GPA

$\begin{array}{lllll}.030 & 1 & .030 & .121 & .729\end{array}$

$\begin{array}{llll}.097 \quad & 1 & .097 \quad .461\end{array}$

Note: $*$ indicates $\mathrm{P}<.05 ; * *$ indicates $\mathrm{P}<.01$

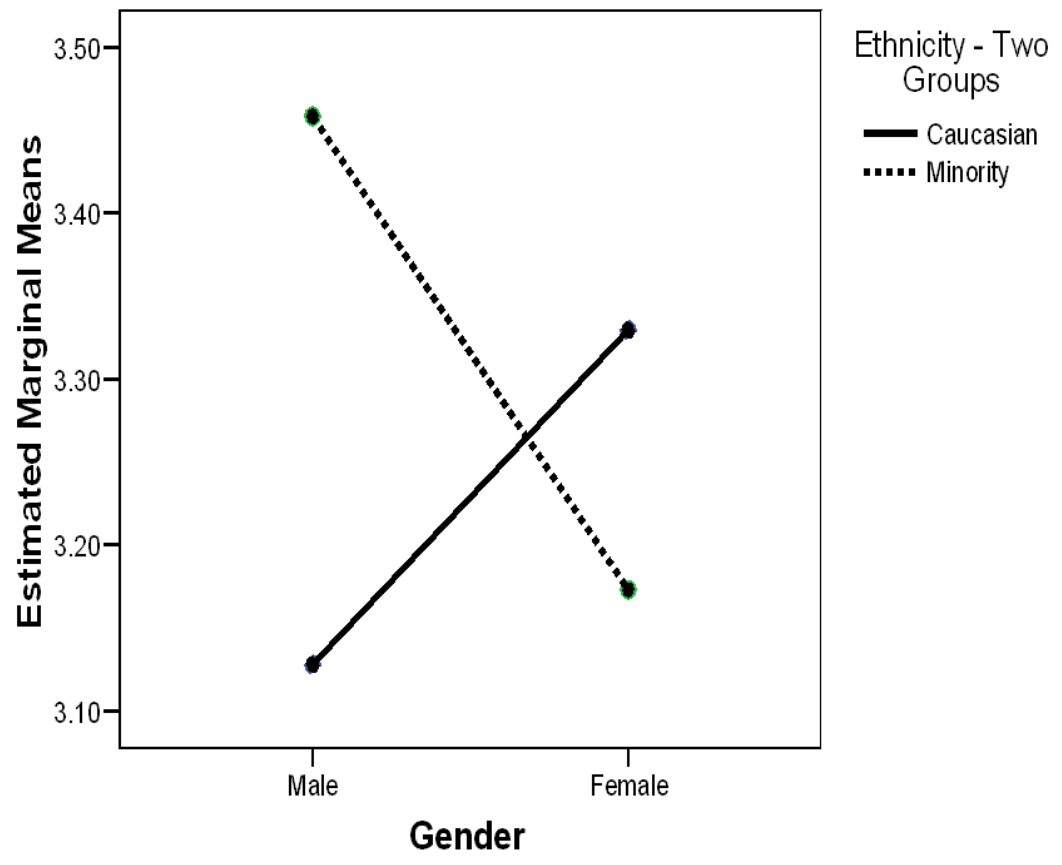

Figure 2. Gender by Ethnicity Interaction Effect Across Relationships 


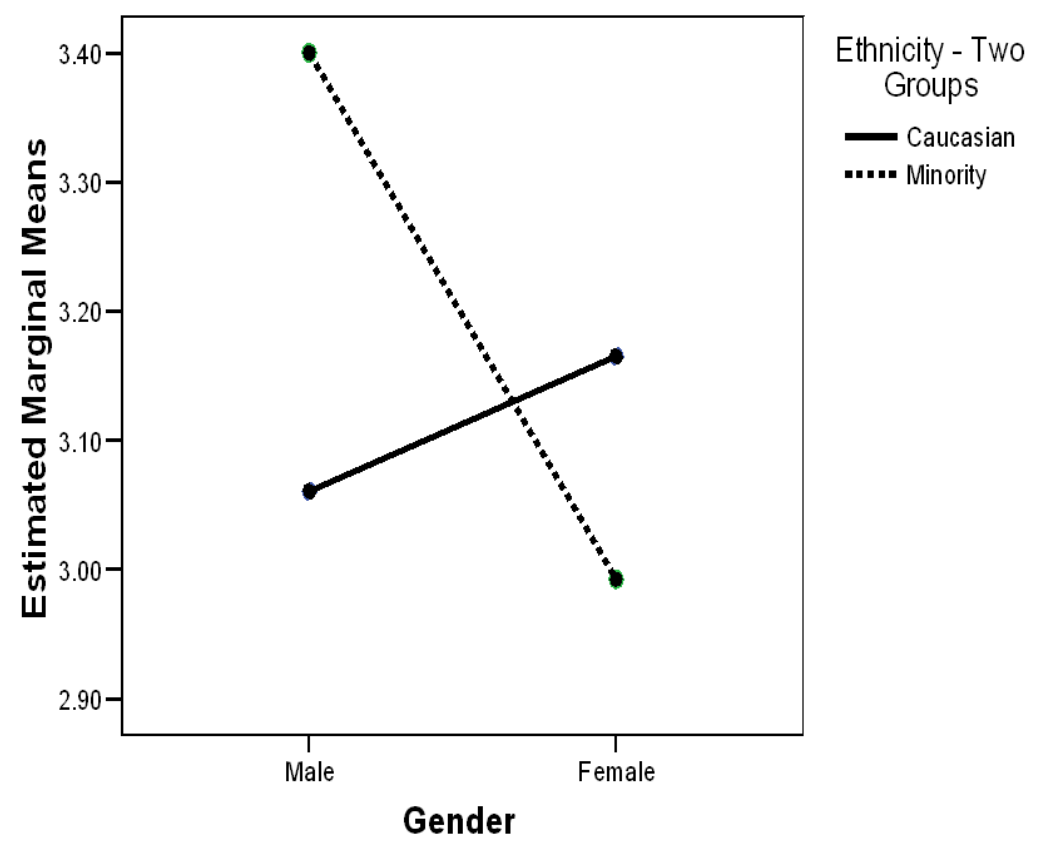

Figure 3. Gender by Ethnicity Interaction Effect Across Making a Difference

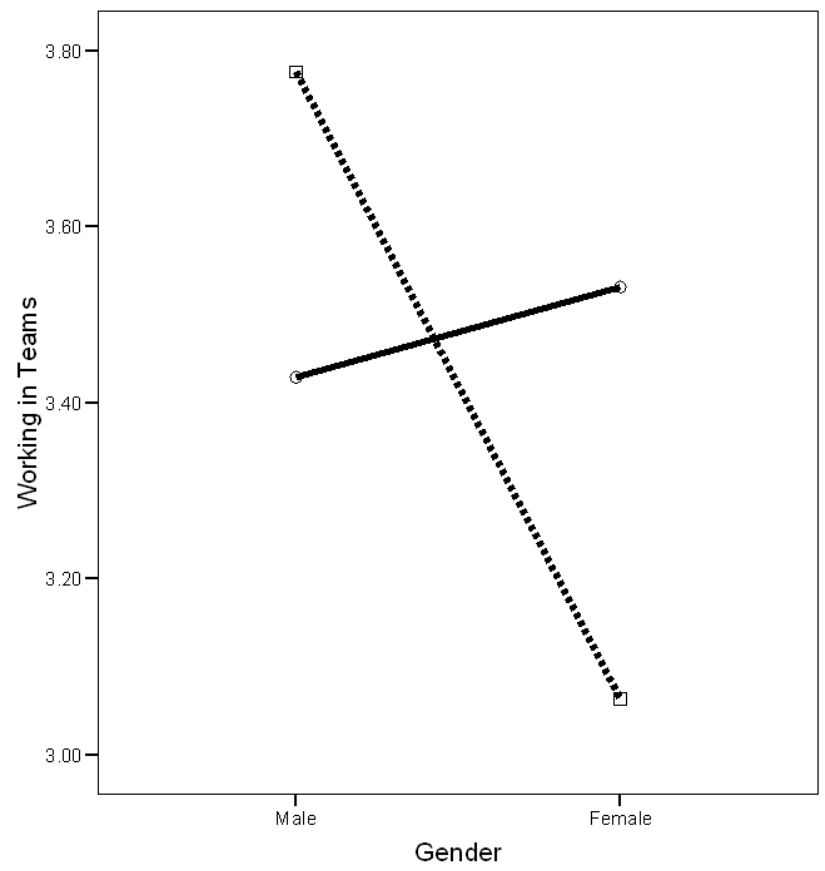

Ethnic 2 groups

..... Minority

Figure 4. Gender by Ethnicity Interaction Effect across Working in Teams 
Table 4. Means and Standard Deviations for Factorial ANOVA

\section{Descriptive Statistics}

\begin{tabular}{|c|c|c|c|c|c|c|}
\hline & Gender & $\begin{array}{l}\text { Ethnicity } \\
\text { Groups }\end{array}$ & - Two & Mean & $\begin{array}{c}\text { Std. } \\
\text { Deviation } \\
\end{array}$ & $\mathrm{N}$ \\
\hline \multirow{9}{*}{$\begin{array}{l}\text { Relationship } \\
\text { At-Risk Students }\end{array}$} & Male & Caucasian & & 3.13 & .51 & 43 \\
\hline & & Minority & & 3.463 & .53 & 8 \\
\hline & & Total & & 3.18 & .52 & 51 \\
\hline & Female & Caucasian & & 3.33 & .40 & 43 \\
\hline & & Minority & & 3.17 & .46 & 13 \\
\hline & & Total & & 3.29 & .42 & 56 \\
\hline & Total & Caucasian & & 3.23 & .47 & 86 \\
\hline & & Minority & & 3.28 & .498 & 21 \\
\hline & & Total & & 3.24 & .47 & 107 \\
\hline \multirow{9}{*}{$\begin{array}{l}\text { Making a Difference } \\
\text { to At-Risk Students }\end{array}$} & Male & Caucasian & & 3.06 & .47 & 43 \\
\hline & & Minority & & 3.40 & .51 & 8 \\
\hline & & Total & & 3.11 & .49 & 51 \\
\hline & Female & Caucasian & & 3.17 & .43 & 43 \\
\hline & & Minority & & 2.99 & .31 & 13 \\
\hline & & Total & & 3.12 & .41 & 56 \\
\hline & Total & Caucasian & & 3.11 & .45 & 86 \\
\hline & & Minority & & 3.15 & .44 & 21 \\
\hline & & Total & & 3.12 & .44 & 107 \\
\hline \multirow[t]{9}{*}{ Working in Teams } & Male & Caucasian & & 3.36 & .41 & 43 \\
\hline & & Minority & & 3.73 & .29 & 8 \\
\hline & & Total & & 3.42 & .41 & 51 \\
\hline & Female & Caucasian & & 3.41 & .49 & 43 \\
\hline & & Minority & & 3.18 & .52 & 13 \\
\hline & & Total & & 3.35 & .50 & 56 \\
\hline & Total & Caucasian & & 3.39 & .45 & 86 \\
\hline & & Minority & & 3.39 & .52 & 21 \\
\hline & & Total & & 3.39 & .46 & 107 \\
\hline
\end{tabular}

\section{Conclusions and Recommendations}

Service-learning programs are well-known and differentiated from other teaching methods in education by their goal of equally benefiting recipient and provider of the service. To accomplish this, service-learning curriculum should have significant academic context and be designed in such a way that ensures both the service enhances the learning and the learning enhances the service. It begs the question, "what enhances service?" 


\section{Macrothink}

The repeated measures ANOVA suggests students perceive building relationships with at-risk students, role modeling to at-risk students, service learning effectiveness, working in teams, and seeking spiritual support were significantly superior to communication, making a difference, or leadership commitment to at risk-students. In addition, teamwork was perceived as significantly more important then all other constructs except role modeling. These five constructs were current actions that were perceived as important to the service learning experience.

On the other hand, communication, leadership, and making a difference were future-centered. In other words, participants perceived those areas they could assess here and now as more important then those areas that could not be assessed without feedback or future visits.

The factorial ANOVA indicated significant main effect differences between genders on teamwork. Males rated teamwork significantly higher then females. Three interaction effects were discovered--Relationship to At-Risk Students, Making a Difference to At-Risk Students, and Working in Teams. In each case, male minorities and female Caucasians rated their perceptions higher than female minorities and male Caucasians.

The research suggests service learning practicum are perceived successful from different viewpoints. For all participants, current-centered perceptions (i.e., relationships, role modeling, service learning effectiveness, spiritual support, and teamwork) were important to their service learning process as compared to future-centered viewpoints (communication, making a difference, and leadership). The focus on existing, here-and-now service learning curriculum was the message.

Relationships, seeking to make a difference, and teamwork experiences affected gender and ethnic groups differently. Male minorities and female Caucasians provided the highest satisfaction ratings as compared to their counterparts. This implies two areas of interest for further study. The first is a concern as to why male Caucasians and female minorities rated those constructs lower. The second suggests the three constructs had a positive effect on male minorities and female Caucasians. Further research is needed to determine reasons for the difference between all participants in gender, ethnicity, current-centered viewpoints, and future-centered viewpoints.

\section{References}

Azusa Pacific University. (2008). Enrollment and persistence. In Office of Institutional

Research Common Data Set: 2007-2008. Retrieved March 10, 2009 from http://www.apu.edu/ir/commondata/2008/b/

Batchelder, T. H. \& Root, S. (1994). Effects of an undergraduate program to integrate academic learning and service: Cognitive, prosocial cognitive, and identity outcomes. Journal of Adolescence 17 (4), 341-355. 
Bringle, R. G., \& Hatcher, J. A. (1996). Implementing service learning in higher education. Journal of Higher Education, 67(2), 221-239.

Eyler, J., Giles Jr., D. E., \& Braxton, J. (1997). The impact of service-learning on college students. Michigan Journal of Community Service Learning, 4, 5-15.

Eyler, J. \& Giles Jr., D. E. (1999). Where's the learning in service-learning? San Francisco: Jossey-Bass.

Hesser, G. (1995). Faculty assessment of student learning: Outcomes attributed to service-learning and evidence of changes in faculty attitudes about experiential education. Michigan Journal of Community Service Learning, 2, 33-42.

Kezar, A. (2002). Assessing community service-learning: Are we identifying the right outcomes? About Campus, 14-20.

Moely, B. E., McFarland, M., Miron, D., Mercer, S., \& Ilustre, V. (2002). Changes in college students' attitudes and intentions for civic involvement as a function of service-learning experiences. Michigan Journal of Community Service Learning, 9(1), 18-26.

Oates, K. K., \& Leavitt, L. H. (2003). Service-learning and learning communities: Tools for integration and assessment. Washington, DC: Association of American College and Universities.

The National Service-Learning Clearinghouse. (2007). What is service learning? 24 November 2007, from the World Wide Web: http://www.servicelearning.org.

Steinke, P. \& Buresh, S. (2002). Cognitive outcomes of service-learning: Reviewing the past and glimpsing the future. Michigan Journal of Community Service Learning, 8(2), 5-14.

Watts, M. M. (2003). Passion for learning, passion for like. New Directions for Teaching and Learning, 94, 61-67.

U.S. Census Bureau. (2000). Profile of general demographic characteristics: Azusa city, california. Washington, D.C.:U.S. Census Bureau. Retrieved July 17, 2008 from http://censtats.census.gov/data/CA/1600603386.pdf 